\title{
Dietary Intake and Health Status of Elderly Patients With Type 2 Diabetes Mellitus: Cross-sectional Study Using a Mobile App in Primary Care
}

Joane Diomara Coleone ${ }^{1}$, BSc, MSc; Ericles Andrei Bellei², BTech, MSc; Mateus Klein Roman ${ }^{2}$, BSc; Vanessa Ramos Kirsten ${ }^{3,4}$, BSc, MSc, PhD; Ana Carolina Bertoletti De Marchi ${ }^{1,2}$, BSc, MSc, PhD

\footnotetext{
${ }^{1}$ School of Physical Education and Physiotherapy, University of Passo Fundo, Passo Fundo, RS, Brazil

${ }^{2}$ Institute of Exact Sciences and Geosciences, University of Passo Fundo, Passo Fundo, RS, Brazil

${ }^{3}$ Department of Foods and Nutrition, Federal University of Santa Maria, Palmeira das Missões, RS, Brazil

${ }^{4}$ Graduate Program in Gerontology, Federal University of Santa Maria, Santa Maria, RS, Brazil
}

\section{Corresponding Author:}

Ericles Andrei Bellei, BTech, MSc

Institute of Exact Sciences and Geosciences

University of Passo Fundo

B5 Building, São José, Highway BR285, Km 292

Passo Fundo, RS, 99052-900

Brazil

Phone: 555433168354

Email: 168729@upf.br

\section{Abstract}

Background: Healthy dietary intake reduces the risk of complications of diabetes mellitus. Using assessment methods helps to understand these circumstances, and an electronic application may optimize this practice.

Objective: In this study, we aimed to (1) assess the dietary intake and health status of elderly patients with type 2 diabetes mellitus (T2DM) in primary care, (2) use a mobile app as a tool for data collection and analysis in the context of primary care, and (3) verify the perceptions of multidisciplinary health professionals regarding app use.

Methods: First, we developed a mobile app comprised of the questions of the Food and Nutrition Surveillance System (SISVAN) of Brazil, which includes a food frequency questionnaire of food categories with a recall of the previous 7 days. Thereafter, we used the app to collect data on the health status and dietary intake of 154 participants, aged 60-96 years, diagnosed with T2DM, and under treatment in primary care centers in the northern region of Rio Grande do Sul, Brazil. We also collected participants' demographic, anthropometric, biochemical, and lifestyle variables. The associations between dietary intake and other variables were tested using chi-square tests with a 5\% significance level. Regarding the app, we assessed usability and acceptance with 20 health professionals.

Results: Between August 2018 and December 2018, participants had an intake in line with recommended guidelines for raw salads $(57.1 \%)$, fruits $(76.6 \%)$, milk products $(68.2 \%)$, fried foods $(72.7 \%)$, savory biscuits $(60.4 \%)$, cookies or sweets $(72.1 \%)$, and sugary drinks (92.9\%) Meanwhile, the consumption of beans (59.7\%), pulses and cooked vegetables (73.4\%), and processed meat products $(59.7 \%)$ was not in line with the guidelines. There were statistically significant differences in meeting the recommended guidelines among participants of different genders $(P=.006$ and $P=.035$ for the intake of fried foods and sugary drinks, respectively), place of residence ( $P=.034$ for the intake of cookies and sweets), family history of diabetes $(P<.001$ for the intake of beans), physical activity engagement ( $P=.003$ for the intake fresh fruits), history of smoking ( $P=.001$ for the intake of raw salads), and presence of coronary disease ( $P=.050$ for the intake of pulses and cooked vegetables). The assessment of usability resulted in a mean score of 71.75 points. Similarly, the assessment of the 15 acceptance questions revealed high scores, and the qualitative questions revealed positive perceptions.

Conclusions: We identified that most participants complied with recommended intake guidelines for 7 of 10 categories in the SISVAN guidelines. However, most participants were overweight and had nutritional and clinical disorders, which justifies further investigations in this population. The app was well-rated by health professionals and considered a useful and promising tool for collecting and analyzing data in primary care settings. 
(JMIR Form Res 2021;5(8):e27454) doi: 10.2196/27454

\section{KEYWORDS}

eating; mobile applications; primary health care; aged; type 2 diabetes mellitus

\section{Introduction}

An aging population, the prevalence of obesity, sedentary lifestyles, and urbanization processes have been contributing to the increase in type 2 diabetes mellitus (T2DM) worldwide [1]. In public health, especially in developing countries such as Brazil, T2DM results in high economic and social costs for its treatment and care, due to the association with several complications [2]. A healthy dietary intake reduces the risk of complications to maintain acceptable health standards and functional capacity [3]. However, patients with T2DM, particularly the elderly, have difficulty adhering to a healthy diet, as they may perceive diet plans as prohibitive, restrictive, and challenging [4]. In these circumstances, understanding dietary habits requires appropriate assessment tools.

A systematic review [5] revealed that the main method for assessing dietary intake in public health settings for elderly patients with T2DM can be classified as a food frequency questionnaire. However, the application of the questionnaire is paper-based in most cases, which is time-consuming. New technologies offer great opportunities to fully assess the intake of foods and nutrients of large populations at relatively low cost and in real time [6]. These tools have fast access, full-time availability, and potential access through mobile apps, showing practicality for hospitals, clinics, and outpatient clinics [7]. In Brazil's public health system, primary care is the main strategy of surveillance, which also aims to provide comprehensive health care, specialized services, and hospital care, as well as health promotion and disease prevention activities [8]. In these settings, although still not widespread, the use of technology is promising $[9,10]$, in particular to facilitate the work of multidisciplinary health professionals. Therefore, initiatives to introduce digital tools are relevant to test possibilities and improve primary care in Brazil.

In this study, we aimed to (1) assess the dietary intake and health status of elderly patients with T2DM in primary care, (2) use a mobile app as a tool for data collection and analysis in the context of primary care, and (3) document the perceptions of multidisciplinary health professionals regarding app use.

\section{Methods}

\section{Overview}

We considered the sequences and processes from several studies in the literature involving software applications [11-13] to select, develop, and apply an assessment tool complying with the DIET@NET partnership guidelines [14]. We performed a cross-sectional study between August 2018 and December 2018 in public primary health centers in 4 small towns in the northern region of Brazil's Rio Grande do Sul, namely Estação, Erebango, Getúlio Vargas, and Ipiranga do Sul, which had 27,079 inhabitants in the last official census. This study was conducted according to the guidelines laid down in the Declaration of
Helsinki, and all procedures involving research study participants were approved by the ethics committee of the University of Passo Fundo under opinion number 2660304. Written informed consent was obtained from all participants. According to national regulations, participants were not compensated.

\section{Sampling, Subjects, and Recruitment}

For the sample calculation, we considered the total population of elderly patients who were diagnosed with T2DM by the public health control from the cities investigated and attended a primary care center $(\mathrm{N}=257)$, with an expectation of a dietary intake $50 \%$ in line with the Food and Nutrition Surveillance System (SISVAN) of Brazil guidelines, acceptable error of 5\%, and a confidence level of $95 \%$, resulting in a target sample size of 154 individuals. The inclusion criteria were 60 years of age or older; T2DM diagnosis, either by self-report or confirmed by examinations in the patient history (fasting glycemia or glycated hemoglobin $\left[\mathrm{HbA}_{1 \mathrm{c}}\right]$ ); and cognitive ability confirmed by the Mini-Mental State Examination [15]. Through phone calls, we randomly called participants to attend the primary health center for an interview. We invited participants until we reached the required sample. All participants signed an informed consent form.

\section{Development of a Mobile App for Dietary Assessment}

Initially, we performed a systematic mapping to investigate the different methods for assessing the dietary intake of adults and the elderly [5]. We observed that the main assessment method was a food frequency questionnaire. However, the questionnaires are usually applied manually. To optimize time and resources, we wanted to use an electronic method for collecting and processing the questionnaires.

In this study, we used the Dietary Intake Form proposed by SISVAN [16], which is an initiative from the Brazilian Ministry of Health. The form is a food frequency questionnaire with a recall period of the previous 7 days and is comprised of 10 categories, which relate to a healthy diet (eg, daily intake of beans, fresh fruits, vegetables, and milk) or to nonrecommended practices (eg, frequent intake of fried foods, processed meat products, cookies, sweets, and soft drinks). SISVAN guidelines recommend an intake of 7 serves per week of raw salad, pulses and cooked vegetables, fresh fruit, and milk or yogurt; 5 or more serves per week of beans; and 0-1 serves per week of fried foods, processed meat products, savory biscuits, cookies or sweets, and sugary drinks.

Previously, a mobile app addressing SISVAN had been developed for use with inpatients [7]. Hence, we developed a new version, with improved functionalities adapted to primary care outpatients, called Diabetes Food Control 2. The app now includes questions on demographic and economic characteristics (eg, marital status, self-reported skin color, education, income, and occupation), clinical and nutritional history, time from 
diagnosis, family history of diabetes, medication intake, presence of comorbidities, nutritional monitoring, lifestyle, physical activity, smoking, and alcohol consumption. The Brazilian Institute of Industrial Property granted us a software registration certificate under number BR5120190010540.

The app (Figure 1) was designed so that health care professionals could use it in primary health care centers to assess the dietary intake and health status of outpatients with T2DM, addressing the recommendations of Brazil's Ministry of Health [16]. Using the app, we intended to optimize data collection and make the usage of apps a more consistent practice in primary care settings. The app's report provides straightforward information on whether the patient meets the SISVAN criteria related to food intake and anthropometric measurements. It also provides personalized feedback for patients in the form of a report they can receive by email.

Figure 1. Screenshots of the Diabetes Food Control 2 mobile app showing patient data collection forms and feedback on the data collected.

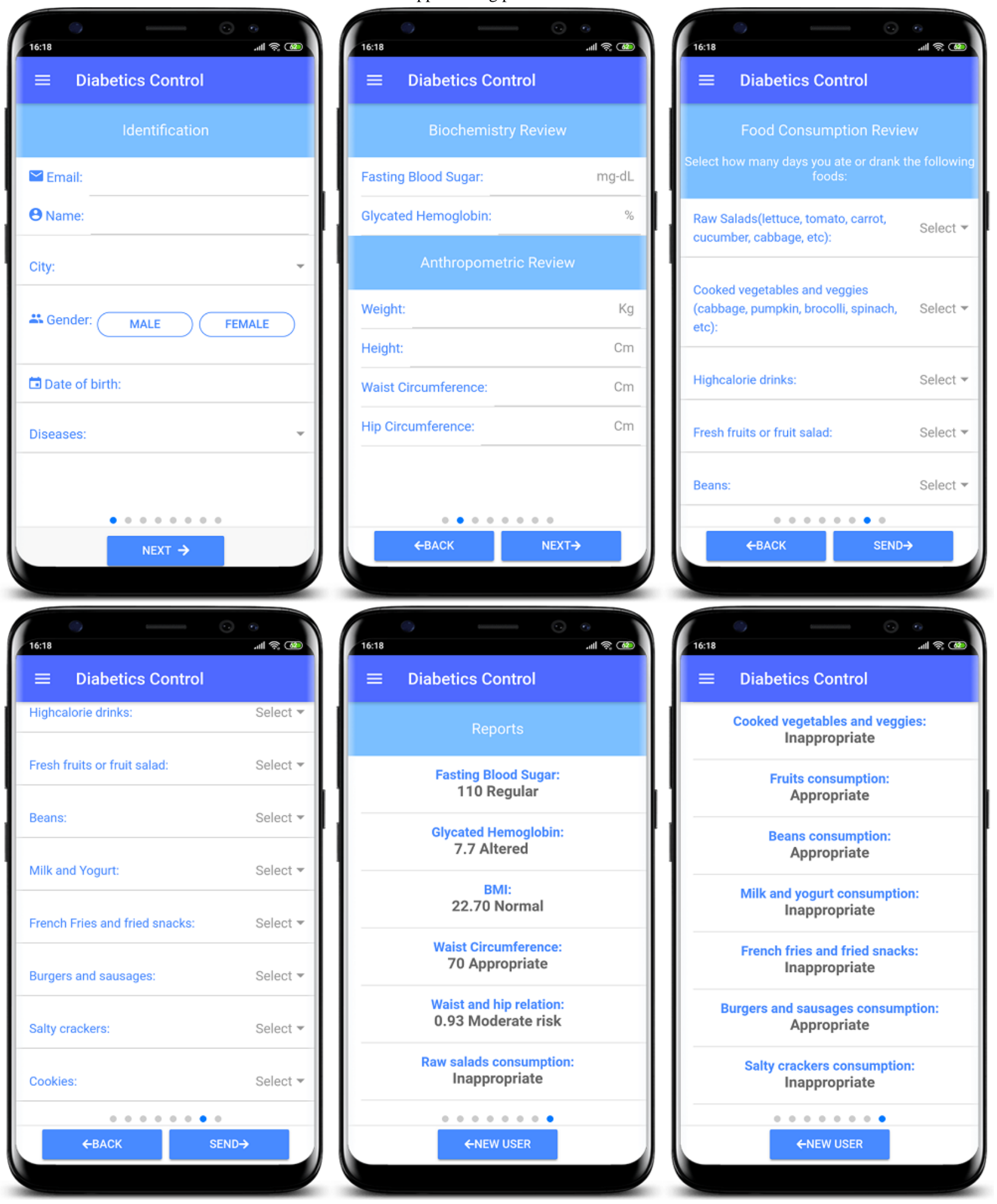




\section{Procedures}

We collected all data with the SISVAN questionnaire using the Diabetes Food Control 2 app. In the public primary health centers selected for the study, the same dietitian researcher interviewed each participant to simultaneously fill out the questionnaire on the app. The dietitian also collected demographic and economic data such as marital status, self-reported skin color, level of education, income, and occupation. The participants followed the use of the app during the entire interview and interacted by filling out their demographic information.

To evaluate nutritional status, we analyzed body weight $(\mathrm{kg})$, height $(\mathrm{cm})$, and waist and hip circumferences $(\mathrm{cm})$. For stature measurement, we used a $200-\mathrm{cm}$ stadiometer with a scale of 0.2 centimeters. To assess weight, we used a Welmy digital scale with a capacity of $150 \mathrm{~kg}$. We took all measurements according to the recommendations of the Brazilian Ministry of Health [17]. Using the measured height and weight, the app calculated the BMI and the classification of nutritional status according to the guidelines of the Pan American Health Organization [18].

The dietitian assessed waist circumference with a measuring tape at the smallest curvature between the ribs and the iliac crest, without compressing the skin. For waist circumference, the categories were low risk (men $<94 \mathrm{~cm}$; women $<80 \mathrm{~cm}$ ), high risk (men $\geq 94 \mathrm{~cm}$; women $\geq 80 \mathrm{~cm}$ ), and very high risk (men $\geq 102 \mathrm{~cm}$; women $\geq 88 \mathrm{~cm}$ ). We measured hip circumference in centimeters in a horizontal plane at the region of the greatest gluteal protuberance. We calculated the waist-to-hip ratio according to the cutoff points recommended by the World Health Organization [19]. For waist-to-hip ratio, the categories were low risk (men $<0.9$; women $<0.8$ ), moderate risk (men 0.9-0.95; women 0.8-0.85), and high risk (men $>0.95$; women $>0.85$ ).

To assess glycemia, we asked the primary health center in each town to conduct a $\mathrm{HbA}_{1 \mathrm{c}}$ test. All blood tests were collected and evaluated by trusted outsourced laboratories that were contracted by the primary health center. All handling procedures were carried out in accordance with national quality and safety standards and under the supervision of the researchers. A value of $8.0 \%$ was the standard reference value, as recommended by the American Diabetes Association for individuals aged over 60 years [20]. We also assessed fasting capillary glycemia, which a nursing professional verified at the time of the questionnaire application using an Accu-Check Active glucometer. In this case, $70-110 \mathrm{mg} / \mathrm{dL}$ was the standard reference value [20].

During the interview, the dietitian also investigated the clinical and nutritional history of participants, time from T2DM diagnosis, family history of diabetes, and medication intake. The dietitian registered information on the presence of comorbidities, such as hypertension and dyslipidemia, and whether the participant had received any nutritional guidance, engaged in physical activities routinely, smoked, and consumed alcohol. At the end of the interview, the participant received nutritional instructions for better glycemic control and a report generated by the app showing his or her dietary and health status according to the SISVAN guidelines.

\section{Assessment of the Mobile App With Health Professionals}

We also assessed the mobile app with 20 health professionals, including 4 medical doctors, 8 registered nurses, and 8 community health agents (registered nurses and licensed practical nurse) who worked in the primary health centers. Individually, we presented the app and described its functionalities and form of use. We let each professional test and interact with the app and fill out the questionnaire once with dummy data, which we discarded later. After the professionals tested the app, we applied a questionnaire to assess usability. To assess usability, we used an adaptation of the System Usability Scale [21]. To analyze acceptance, we used a questionnaire from the Technology Acceptance Model (TAM) [22]. Last, we asked the health professionals the following 3 descriptive questions: Have you ever used a mobile app in clinical practice? How was your experience with using the Diabetes Food Control 2? What changes do you suggest for this app to make it more useful or applicable to clinical practice? The opinions of professionals from the primary health centers would allow us to understand the potential for implementing the app in clinical practice.

\section{Data Analysis}

Participants' dietary intakes were summarized and compared by all the demographic, nutritional, biochemical, and lifestyle variables. Intake was classified according to whether it was in line with SISVAN guidelines [16]. We used SPSS 22.0 statistical software (IBM Corp, Armonk, NY) to analyze the quantitative data. Basic quantitative data are described as mean, SD, and median. Categorical data are described by simple frequencies. The associations between dietary intake and demographic, nutritional, biochemical, and lifestyle variables were tested using chi-square tests, considering a 5\% significance level for all analyses. For the qualitative data, we assessed the data in groups, following the model proposed by Minayo [23].

\section{Results}

\section{Participants}

Table 1 presents the demographic characteristics. Most of the participants were women, married, with self-reported white skin color, residents of an urban area, with $<4$ years of education, retired, with family income between 4 and 10 minimum wages, and presenting with a family history of diabetes. 
Table 1. Demographic characteristics of 154 patients with type 2 diabetes mellitus in primary care in Rio Grande do Sul, Brazil in 2018.

\begin{tabular}{|c|c|}
\hline Characteristic & $\mathrm{n}(\%)$ \\
\hline \multicolumn{2}{|l|}{ Gender } \\
\hline Female & $107(69.5)$ \\
\hline Male & $47(30.5)$ \\
\hline \multicolumn{2}{|l|}{ Age (years) } \\
\hline $60-69$ & $67(43.5)$ \\
\hline $70-79$ & $63(40.9)$ \\
\hline $80-89$ & $22(14.3)$ \\
\hline$\geq 90$ & $2(1.3)$ \\
\hline \multicolumn{2}{|l|}{ Marital status } \\
\hline Single & $5(3.2)$ \\
\hline Married & $101(65.6)$ \\
\hline Divorced & $5(3.2)$ \\
\hline Widow(er) & $43(27.9)$ \\
\hline \multicolumn{2}{|l|}{ Self-reported skin color } \\
\hline White & $130(84.4)$ \\
\hline Brown & $15(9.7)$ \\
\hline Black & $9(5.8)$ \\
\hline \multicolumn{2}{|l|}{ Place of residence } \\
\hline Urban area & $126(81.8)$ \\
\hline Rural area & $28(18.2)$ \\
\hline \multicolumn{2}{|l|}{ Education level } \\
\hline Elementary school & $137(89.0)$ \\
\hline High school & $4(2.5)$ \\
\hline Higher education & $3(1.9)$ \\
\hline Illiterate & $10(6.5)$ \\
\hline \multicolumn{2}{|l|}{ Family income (minimum wages in Brazil) } \\
\hline Between 10 and 20 minimum wages & $12(7.8)$ \\
\hline Between 4 and 10 minimum wages & $70(45.5)$ \\
\hline Between 2 and 4 minimum wages & $51(33.1)$ \\
\hline Up to 2 minimum wages & $21(13.6)$ \\
\hline
\end{tabular}

Lifestyle, Anthropometric, and Glucose Measurements

Table 2 presents the data on clinical characterization and lifestyle. The majority reported using only oral hypoglycemic agents for T2DM treatment, having dyslipidemia and systemic arterial hypertension, and using medications for hypertension. Most respondents also reported having received some nutritional guidance but not performing nutritional monitoring. Most participants reported having never smoked, not consuming alcohol, and not performing physical activity. 
Table 2. Clinical characteristics and lifestyle of 154 patients with type 2 diabetes mellitus in primary care in Rio Grande do Sul, Brazil in 2018.

\begin{tabular}{|c|c|}
\hline Characteristic & $\mathrm{n}(\%)$ \\
\hline Family history of diabetes (yes) & $99(64.3)$ \\
\hline \multicolumn{2}{|l|}{ Diabetes medication } \\
\hline Oral hypoglycemic agents & $98(63.6)$ \\
\hline Insulin only & $8(5.2)$ \\
\hline Insulin and hypoglycemic agents & $35(22.7)$ \\
\hline None & $13(8.4)$ \\
\hline Self-reported hypertension (yes) & $130(84.4)$ \\
\hline Medication use for hypertension (yes) & $76(97.4)$ \\
\hline Self-reported dyslipidemia (yes) & $88(57.1)$ \\
\hline Has received nutritional guidance (yes) & $89(57.8)$ \\
\hline \multicolumn{2}{|l|}{ Professional providing guidance } \\
\hline Physician & $37(24.0)$ \\
\hline Dietitian & $37(24.0)$ \\
\hline Nurse & $4(2.6)$ \\
\hline Nutritional monitoring (yes) & $2(1.3)$ \\
\hline \multicolumn{2}{|l|}{ Smoking status } \\
\hline Never smoked & $107(69.5)$ \\
\hline Former smoker & $38(24.7)$ \\
\hline Smokes currently & $9(5.8)$ \\
\hline \multicolumn{2}{|l|}{ Frequency of alcohol consumption } \\
\hline Never & $121(78.6)$ \\
\hline Less than 1 dose per month & $22(14.3)$ \\
\hline Between 1 and 3 doses per month & $7(4.5)$ \\
\hline Between 4 and 7 doses per month & $4(2.6)$ \\
\hline Engaged in physical activity (yes) & $63(40.9)$ \\
\hline
\end{tabular}

Table 3 presents the characterization of nutritional status. We identified that most participants were obese and had a waist circumference indicating a very high risk of metabolic disorders, a waist-to-hip ratio categorized as high risk, altered capillary glycemia, and altered glycated hemoglobin. As for comorbidities, we identified that $51.9 \%(80 / 154)$ of respondents reported none of the diseases investigated, $31.2 \%$ (48/154) with coronary disease, $16.9 \%$ (26/154) with diabetic retinopathy, $16.9 \%(16 / 154)$ with depression, 5.8\% (9/154) with kidney disease, $1.3 \%(2 / 154)$ with diabetic neuropathy, and $1.3 \%$ $(2 / 154)$ had received a diagnosis of diabetic foot. 
Table 3. Characterization of nutritional and biochemical status of 154 patients with type 2 diabetes mellitus in primary care in Rio Grande do Sul, Brazil in 2018.

\begin{tabular}{|c|c|}
\hline Indicator & Value \\
\hline Body mass index $\left(\mathrm{kg} / \mathrm{m}^{2}\right)$, mean $(\mathrm{SD})$ & $31.48(5.95)$ \\
\hline \multicolumn{2}{|l|}{ Body mass index, n (\%) } \\
\hline Underweight $\left(<23 \mathrm{~kg} / \mathrm{m}^{2}\right)$ & $7(4.5)$ \\
\hline Normal weight $\left(\geq 23 \mathrm{~kg} / \mathrm{m}^{2}\right.$ to $<28 \mathrm{~kg} / \mathrm{m}^{2}$ ) & $34(22.1)$ \\
\hline Overweight $\left(\geq 28 \mathrm{~kg} / \mathrm{m}^{2}\right.$ to $\left.<30 \mathrm{~kg} / \mathrm{m}^{2}\right)$ & $25(16.2)$ \\
\hline Obesity $\left(\geq 30 \mathrm{~kg} / \mathrm{m}^{2}\right)$ & $88(57.1)$ \\
\hline Waist circumference $(\mathrm{cm})$, mean $(\mathrm{SD})$ & $108.2(13.2)$ \\
\hline \multicolumn{2}{|l|}{ Waist circumference, $\mathrm{n}(\%)$} \\
\hline Low risk (men $<94 \mathrm{~cm}$; women $<80 \mathrm{~cm}$ ) & $5(3.2)$ \\
\hline High risk (men $\geq 94 \mathrm{~cm}$; women $\geq 80 \mathrm{~cm}$ ) & $12(7.8)$ \\
\hline Very high risk (men $\geq 102 \mathrm{~cm}$; women $\geq 88 \mathrm{~cm}$ ) & $137(89.0)$ \\
\hline Waist-to-hip ratio, mean (SD) & $0.999(0.081)$ \\
\hline \multicolumn{2}{|l|}{ Waist-to-hip ratio, $\mathrm{n}(\%)$} \\
\hline Low risk (men <0.9; women <0.8) & $1(0.6)$ \\
\hline Moderate risk (men 0.90:0.95; women 0.80:0.85) & $6(3.9)$ \\
\hline High risk $($ men $>0.95$; women $>0.85$ ) & $147(95.5)$ \\
\hline Capillary glycemia (mg/dL), mean (SD) & $155(48)$ \\
\hline \multicolumn{2}{|l|}{ Capillary glycemia, n (\%) } \\
\hline Normal $(70-110 \mathrm{mg} / \mathrm{dL})$ & $54(35.1)$ \\
\hline Altered $(<70$ and $>110 \mathrm{mg} / \mathrm{dL})$ & $100(64.9)$ \\
\hline $\mathrm{HbA}_{1 \mathrm{c}}$, mean $(\mathrm{SD})$ & $7.4(1.4)$ \\
\hline Normal $(\leq 8.0 \%)$ & $45(29.2)$ \\
\hline Altered $(>8.0 \%)$ & $50(32.5)$ \\
\hline Not collected & $59(38.3)$ \\
\hline
\end{tabular}

\section{Dietary Intake}

Among the participants, $82.5 \%(127 / 154)$ ate breakfast, 50\% $(77 / 154)$ ate a morning snack, $100 \%(154 / 154)$ ate lunch, $70.1 \%$ $(108 / 154)$ ate dinner, and only $9.1 \%(14 / 154)$ ate supper. Most of them $(139 / 154,90.3 \%)$ described a usual diet in the week prior to the study, $85.1 \%(131 / 154)$ reported not adding salt in prepared food, and $52.6 \%$ (81/154) stated using vegetable oil or butter. Most participants had an intake of raw salads, fruits, milk products, fried foods, savory biscuits, cookies or sweets, and sugary drinks in line with recommended guidelines. Meanwhile, the intake of beans, pulses and cooked vegetables, and processed meat products were not in line with recommended guidelines. Figure 2 summarizes the food frequency data for the number of serves per week and the classification according to the SISVAN guidelines. Absolute values are available in Multimedia Appendix 1. 
Figure 2. Food frequency according to the number of servings per week and classification according to the Food and Nutrition Surveillance System of Brazil (SISVAN) guidelines from a sample of 154 patients with type 2 diabetes mellitus in primary care in Rio Grande do Sul, Brazil in 2018.

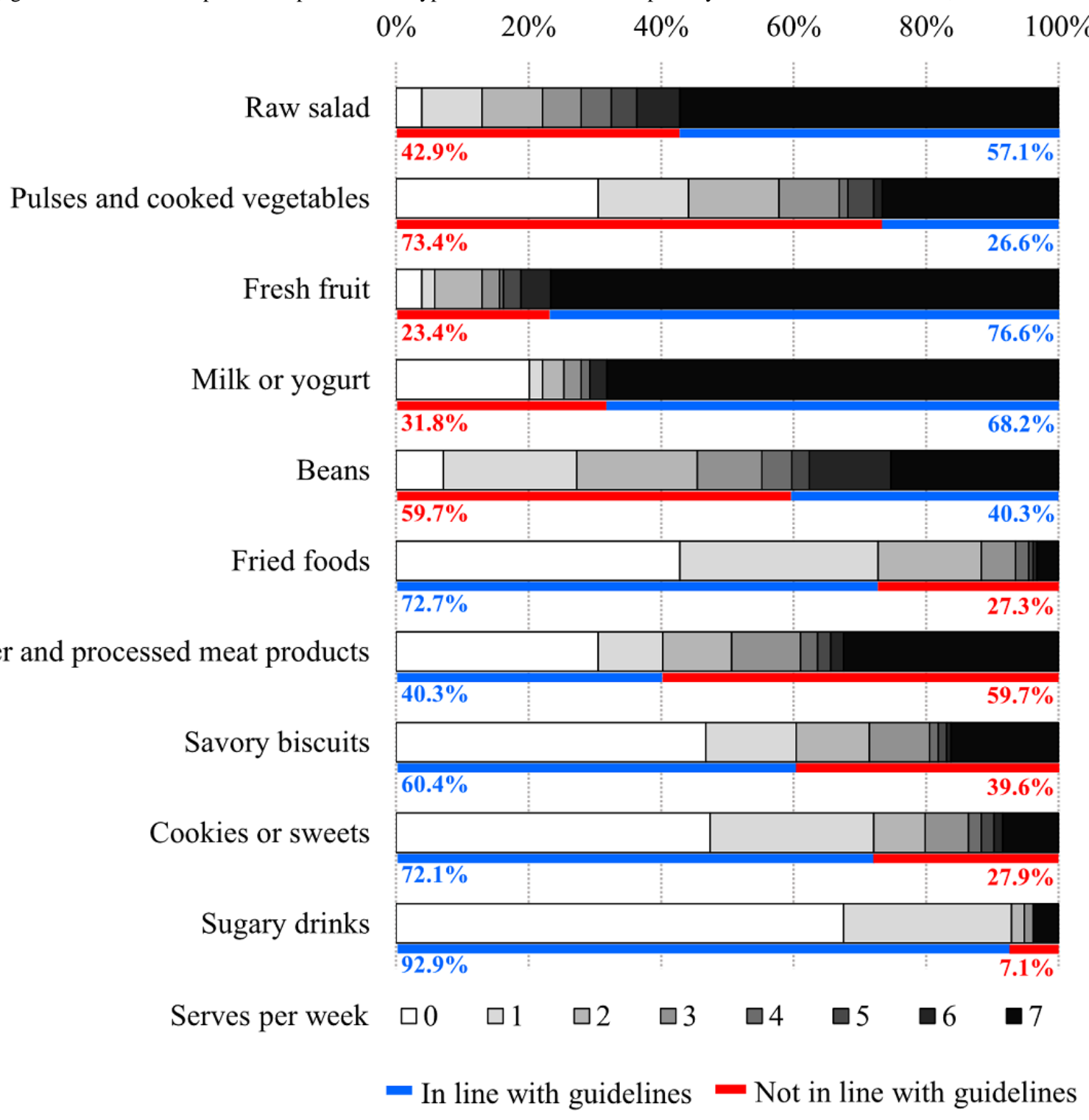

We compared the association between dietary intake with the demographic variables (Multimedia Appendix 2) and with lifestyle, nutritional, and biochemical variables (Multimedia Appendix 3). Statistically, we identified that women had healthier behaviors regarding the intake of fried foods $\left(\chi_{1}^{2}=7.963, P=.006\right)$ and sugary drinks $\left(\chi_{1}^{2}=6.127, P=.035\right)$. As for the place of residence, respondents living in a rural area had a more appropriate intake of cookies and sweets than residents living in an urban area $\left(\chi_{1}^{2}=5.035, P=.034\right)$. Participants without a family history of T2DM had a more appropriate intake of beans $\left(\chi_{1}^{2}=15.170, P<.001\right)$. We detected a more appropriate fruit intake in participants who engaged in physical activity $\left(\chi_{1}^{2}=8.955, P=.003\right)$. We also found that the lower the rate of smoking, the more adequate the intake of raw salad $\left(\chi_{1}^{2}=13.034, P=.001\right)$. Participants with coronary disease reported a more appropriate intake of pulses and cooked vegetables $\left(\chi_{1}^{2}=4.223, P=.050\right)$.

\section{Health Professionals' Perceptions About Using the Mobile App}

The usability assessment with the System Usability Scale generates a score that should be $\geq 68$ points to determine satisfactory results. The assessment of the Diabetes Food Control 2 by health professionals resulted in a mean of 71.75 points, confirming satisfactory usability. Figure 3 presents the responses from health professionals to the TAM questionnaire [22]. The health professionals also answered 3 descriptive questions, depicted in Textbox 1. 
Figure 3. Responses from 20 multidisciplinary, primary care health professionals to the acceptance questionnaire assessing the Diabetes Food control app in Rio Grande do Sul, Brazil in 2018.

$$
\begin{gathered}
\text { I think Diabetes Food Control } 2 \text { is important to the patient's } \\
\text { health care } \\
\text { I think Diabetes Food Control } 2 \text { is useful for managing the } \\
\text { patient's health }
\end{gathered}
$$

Using Diabetes Food Control 2 makes taking care of the health a more interesting task

Diabetes Food Control 2 helps me to keep track of the patient's health condition and history

Diabetes Food Control 2 increases the care with the patient's health

Diabetes Food Control 2 motivates the involvement in controlling the health

I think my interaction with Diabetes Food Control 2 is clear and understandable

I think my interaction with Diabetes Food Control 2 does not require a lot of mental effort

Diabetes Food Control 2 is easy to use

It's easy to learn how to use Diabetes Food Control 2

I was instructed on how to use Diabetes Food Control 2

The researcher knows about Diabetes Food Control 2 and helped me to understand it

It would be better to use Diabetes Food Control 2 instead of a current monitoring method

The results of using Diabetes Food Control 2 are unquestionable

I will continue to use Diabetes Food Control 2 to take care of patient's health

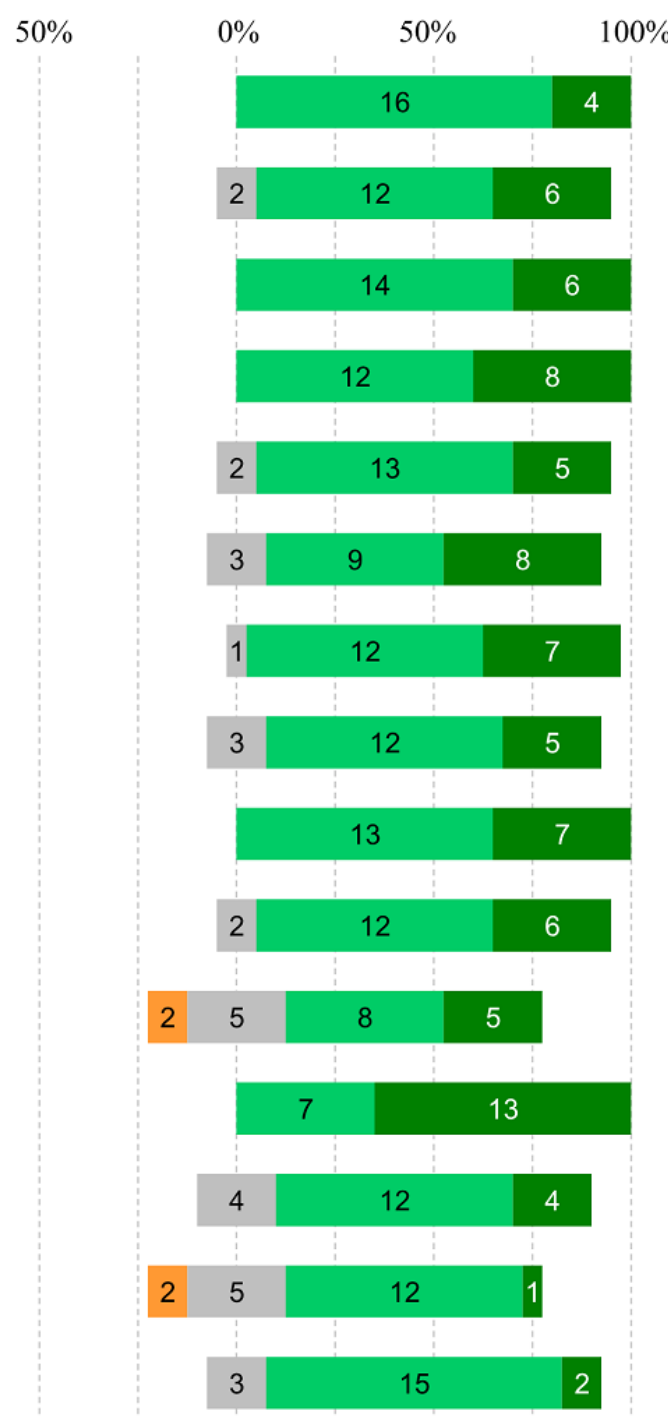

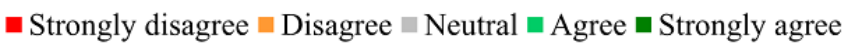

Textbox 1. Health professionals' perceptions about using an app in primary care.

1. "Have you ever used a mobile app in clinical practice?" No participant had used apps in professional practice.

2. "How did you experience the use of Diabetes Food Control 2?" Among the responses, the professionals mentioned they would have improved knowledge on dietary monitoring of patients, agility and practicality in data collection, higher information reliability, and a more significant scientific basis to guide patients.

3. "What changes do you suggest for this app to make it more useful or applicable to clinical practice" Most professionals said there was no need to change the app because it was already adequate. Among the suggestions for improvements, some professionals mentioned the possibility of having an option to increase the font size in the app (accessibility option), having instructions on how to measure anthropometric variables (eg, where to measure the waist and where to measure the hip), showing the percentage of questionnaire completion, and showing the total completion time.

\section{Discussion}

\section{Principal Findings}

This study assessed various aspects of the nutrition of elderly patients diagnosed with T2DM in the context of primary health in line with SISVAN guidelines, which is a national parameter in Brazil. For data collection, we developed and evaluated a new app based on recommendations from medical associations and literature studies. Interesting insights are presented about the use of the app and the health professionals' perceptions about its features and the possibility of using it in the context of primary health.

On nutritional assessments, the profile found was similar to surveys performed in the same circumstances involving adult 
[24] and elderly [25] patients with T2DM. The anthropometric assessment identified that $73.3 \%$ of the study population was overweight, which is a rate higher than that presented in similar studies. This stresses the need for greater attention to elderly patients with T2DM assisted in basic health care, especially due to the evident metabolic syndrome and the worsened transition from adulthood to the elderly.

In this study, we identified that men had a greater intake of fried foods than women with a similar dietary behavior, as in the study by Linde et al [26], in which men with higher BMIs consumed more fried foods than women. Similar findings were also reported by Cahill et al [27] and Sayon-Orea et al [28]. Regarding the intake of sugary drinks, we identified that women had a more appropriate intake than men, corroborating other studies [29,30]. As for the place of residence, respondents living in a rural area had a more appropriate intake of cookies and sweets than residents in an urban area, which was similar to the findings of Farrell et al [31] regarding foods and beverages with high sugar content.

The literature has already shown that people who engage in physical activity have better dietary habits [32]. In our study, respondents who reported engaging in physical activity had a more appropriate fruit intake. These data corroborate the studies by Tan et al [33] and Alakaam and Lemacks [34], which identified a positive relationship between physical activity and the intake of fruits and vegetables. We also identified an inversely proportional association between salad intake and smoking. Sebastian et al [35] had similar findings, in which salad intake seemed more prevalent among former smokers and people who had never smoked. Besides, the intake of pulses was significantly higher in participants with cardiovascular disease. Other studies have also associated the intake of fruits and vegetables with a lower prevalence of coronary disease and the intake of fiber with a lower prevalence of acute myocardial infarction [36,37]. Interestingly, our findings also suggest that respondents without a family history of diabetes had a more appropriate intake of beans. Some prior studies discuss the relationship between T2DM and the intake of beans. For instance, Ley et al [38] affirmed that a diet rich in vegetables, legumes, and unrefined grains was associated with a lower risk of T2DM, and for diagnosed patients, the intake of such foods improves glycemic levels and lipid control.

The app we developed has several benefits emphasized by health professionals. Other researchers who used mobile apps in dietary intake assessments cited similar advantages. Rangan et al [39] mentioned a reduction in data entry and coding workload for researchers. Meanwhile, Bucher Della Torre et al [40] reaffirmed that electronic assessment helps to prevent some pitfalls of paper-based food records, such as errors in transcription and difficulties in reading what participants have written. There is a growing interest in using smartphones to collect data on dietary assessment [6], considering mobile technology offers a wide range of suitable options to achieve the benefits that technology can deliver [41-43].

Among the 20 respondents, none had used apps in their professional practice. This suggests the need for implementing the use of technology in public health, considering the potential help and benefits provided to professionals. Health professionals also reported that, by using the app, they could thoroughly monitor patients in the long term, considering that the questionnaire is easy to apply and contains all the questions needed for proper monitoring in the context of primary health. Community health agents, who are professionals who visit patients' homes, mentioned that the app could be used by them to counsel the general population regarding nutrition. These professionals receive little prior training on nutrition, and the app would provide a scientific basis so they could provide such care to patients.

\section{Limitations}

The physiological aspect of aging was a limitation of the present study. The potential memory loss of the respondents may have affected their answers to retrospective dietary intake. The length of the questionnaire may have also negatively affected the disposition of participants to respond. Another limitation was the impossibility of measuring the $\mathrm{HbA}_{1 \mathrm{c}}$ of all respondents in the laboratory, due to the lack of financial resources. The app was only used one time; therefore, the long-term effectiveness and usefulness should be studied further.

\section{Conclusions}

The dietary intake of the assessed participants is partly appropriate. However, this population was substantially overweight and presented with metabolic syndrome and poor results in the anthropometric and biochemical assessments. Moreover, there was a low intake of pulses and cooked vegetables and beans and a high intake of processed meat products. Mostly, the findings of this study are similar to others in the literature, which reinforces a concerning reality of the health conditions of elderly patients with T2DM. These findings can guide dietary interventions and health education in similar settings. In addition, this study adds to the health informatics literature that a new app can be used in the context of public health in Brazil. The mobile app was useful in the study and well-rated by health professionals in primary health care settings. Its features are encouraging tools for use in future studies. In this study, the app was developed to completely focus on T2DM in primary care settings in Brazil. For application in other settings or for other health conditions, the development method could be adapted or used in a similar way, but considering the specificity of other chronic diseases and according to the specific guidelines available. Future studies can use this study as an example of a location and features where technology is satisfactorily accepted by health care professionals in the first introduction initiative.

\section{Acknowledgments}

The authors would like to thank the patients and professionals who participated in the assessments. This work was supported in part by the National Council for Scientific and Technological Development (CNPq); State Funding Agency of Rio Grande do Sul (FAPERGS); and Coordination and Improvement of Higher Level or Education Personnel - Brazil (CAPES) - finance code 
001. The authors are solely responsible for designing and performing this study and all its analyses, for drafting and editing the manuscript, and for the final content.

\section{Authors' Contributions}

JC and AM conceived and designed the study. JC and MR acquired the data. JC, EB, VK, and AM analyzed and interpreted the data. JC, EB, and MR drafted the manuscript. JC, EB, VK, and AM critically reviewed the manuscript.

\section{Conflicts of Interest}

None declared.

\section{Multimedia Appendix 1}

Food frequency in absolute number of servings per week.

[DOCX File, 14 KB-Multimedia Appendix 1]

\section{Multimedia Appendix 2}

Intake in line with recommended guidelines categorized by demographic and economic variables.

[DOCX File, 22 KB-Multimedia Appendix 2]

\section{Multimedia Appendix 3}

Intake in line with recommended guidelines categorized by clinical, nutritional, biochemical, and lifestyle variables. [DOCX File, 54 KB-Multimedia Appendix 3]

\section{References}

1. Moura EC, Pacheco-Santos LM, Peters LR, Serruya SJ, Guimarães R. Research on chronic noncommunicable diseases in Brazil: meeting the challenges of epidemiologic transition. Rev Panam Salud Publica 2012 Mar;31(3):240-245. [doi: 10.1590/s1020-49892012000300009] [Medline: 22569699]

2. Bahia LR, Araujo DV, Schaan BD, Dib SA, Negrato CA, Leão MPS, et al. The costs of type 2 diabetes mellitus outpatient care in the Brazilian public health system. Value Health 2011;14(5 Suppl 1):S137-S140 [FREE Full text] [doi: 10.1016/j.jval.2011.05.009] [Medline: 21839888]

3. Pinto de Souza Fernandes D, Duarte MSL, Pessoa MC, Franceschini SDCC, Ribeiro AQ. Evaluation of diet quality of the elderly and associated factors. Arch Gerontol Geriatr 2017 Sep;72:174-180. [doi: 10.1016/j.archger.2017.05.006] [Medline: 28688369]

4. Zanetti ML, Arrelias CCA, Franco RC, Santos MAD, Rodrigues FFL, Faria HTG. [Adherence to nutritional recommendations and sociodemographic variables in patients with diabetes mellitus]. Rev Esc Enferm USP 2015 Aug;49(4):619-625 [FREE Full text] [doi: 10.1590/S0080-623420150000400012] [Medline: 26353099]

5. Coleone JD, Bellei EA, De Marchi ACB. Food consumption and glycemic testing of adults and elderly diabetic patients from Public Health: A systematic review of assessment methods. Diabetes Metab Syndr 2019;13(5):3005-3010. [doi: 10.1016/j.dsx.2018.07.013] [Medline: 30057070]

6. Cade JE. Measuring diet in the 21st century: use of new technologies. Proc Nutr Soc 2017 Aug;76(3):276-282. [doi: 10.1017/S0029665116002883] [Medline: 27976605]

7. Zanchim MC, Kirsten VR, Marchi ACBD. Consumption of dietary intake markers by patients with diabetes assessed using a mobile application. Cien Saude Colet 2018 Dec;23(12):4199-4208 [FREE Full text] [doi: 10.1590/1413-812320182312.01412017] [Medline: 30540003]

8. Paim J, Travassos C, Almeida C, Bahia L, Macinko J. The Brazilian health system: history, advances, and challenges. Lancet 2011 May 21;377(9779):1778-1797. [doi: 10.1016/S0140-6736(11)60054-8] [Medline: 21561655]

9. Debon R, Bellei EA, Biduski D, Volpi SS, Alves ALS, Portella MR, et al. Effects of using a mobile health application on the health conditions of patients with arterial hypertension: A pilot trial in the context of Brazil's Family Health Strategy. Sci Rep 2020 Apr 07;10(1):6009 [FREE Full text] [doi: 10.1038/s41598-020-63057-w] [Medline: 32265476]

10. Volpi SS, Biduski D, Bellei EA, Tefili D, McCleary L, Alves ALS, et al. Using a mobile health app to improve patients' adherence to hypertension treatment: a non-randomized clinical trial. PeerJ 2021;9:e11491. [doi: 10.7717/peerj.11491] [Medline: 34123593]

11. Sauceda A, Frederico C, Pellechia K, Starin D. Results of the Academy of Nutrition and Dietetics' Consumer Health Informatics Work Group's 2015 Member App Technology Survey. J Acad Nutr Diet 2016 Aug;116(8):1336-1338. [doi: 10.1016/j.jand.2016.04.009] [Medline: 27236643] 
12. Bellei EA, Biduski D, Lisboa HRK, De Marchi ACB. Development and Assessment of a Mobile Health Application for Monitoring the Linkage Among Treatment Factors of Type 1 Diabetes Mellitus. Telemed J E Health 2020 Feb;26(2):205-217. [doi: 10.1089/tmj.2018.0329] [Medline: 30724717]

13. Cechetti NP, Bellei EA, Biduski D, Rodriguez JPM, Roman MK, De Marchi ACB. Developing and implementing a gamification method to improve user engagement: A case study with an m-Health application for hypertension monitoring. Telematics and Informatics 2019 Aug;41:126-138. [doi: 10.1016/j.tele.2019.04.007]

14. Cade JE, Warthon-Medina M, Albar S, Alwan NA, Ness A, Roe M, DIET@NET consortium. DIET@ NET: Best Practice Guidelines for dietary assessment in health research. BMC Med 2017 Nov 15;15(1):202 [FREE Full text] [doi: 10.1186/s12916-017-0962-x] [Medline: 29137630]

15. Brucki SMD, Nitrini R, Caramelli P, Bertolucci PHF, Okamoto IH. [Suggestions for utilization of the mini-mental state examination in Brazil]. Arq Neuropsiquiatr 2003 Sep;61(3B):777-781 [FREE Full text] [doi:

10.1590/s0004-282x2003000500014] [Medline: 14595482]

16. Ministério da Saúde. Protocolos do Sistema de Vigilância Alimentar e Nutricional - SISVAN na assistência à saúde. Brasilia: Ministério da Saúde; 2008. URL: https://aps.saude.gov.br/biblioteca/visualizar/MTI4Ng==

17. Ministério da Saúde. Orientações para coleta e análise de dados antropométricos em serviços de saúde: norma técnica do sistema de Vigilância Alimentar e Nutricional - SISVAN. Brasília: Ministério da Saúde; 2011. URL: https://aps.saude.gov.br/ biblioteca/visualizar/MTI4MQ==

18. Multicenter survey aging, health and wellbeing in Latin America and the Caribbean (SABE): preliminary report. Pan American Health Organization. 2001. URL: https://iris.paho.org/handle/10665.2/45879 [accessed 2021-07-24]

19. Physical status: the use of and interpretation of anthropometry, report of a WHO expert committee. World Health Organization. 1995. URL: https://apps.who.int/iris/handle/10665/37003 [accessed 2021-07-24]

20. American Diabetes Association. Standards of Medical Care in Diabetes - 2019: Abridged for Primary Care Providers. Clin Diabetes 2019 Jan;37(1):11-34 [FREE Full text] [doi: 10.2337/cd18-0105] [Medline: 30705493]

21. Brooke J. In: Jordan PW, Thomas B, Weerdmaster BA, McClelland IL, editors. SUS: a quick and dirty usability scale. London, England: Taylor \& Francis; 1996:189-194.

22. Davis FD, Bagozzi RP, Warshaw PR. User Acceptance of Computer Technology: A Comparison of Two Theoretical Models. Management Science 1989 Aug;35(8):982-1003. [doi: 10.1287/mnsc.35.8.982]

23. Minayo MCDS, Gomes SFDR. Pesquisa Social, Teoria, Metodo e Criatividade. Petrópolis: Editora Vozes; 1993.

24. Osonoi Y, Mita T, Osonoi T, Saito M, Tamasawa A, Nakayama S, et al. Relationship between dietary patterns and risk factors for cardiovascular disease in patients with type 2 diabetes mellitus: a cross-sectional study. Nutr J 2016 Feb 04;15:15 [FREE Full text] [doi: 10.1186/s12937-016-0132-6] [Medline: 26847556]

25. Vitoi NC, Fogal AS, Nascimento CDM, Franceschini SDCC, Ribeiro AQ. Prevalence and associated factors of diabetes in the elderly population in Viçosa, Minas Gerais, Brazil. Rev Bras Epidemiol 2015;18(4):953-965 [FREE Full text] [doi: 10.1590/1980-5497201500040022] [Medline: 26982308]

26. Linde JA, Utter J, Jeffery RW, Sherwood NE, Pronk NP, Boyle RG. Specific food intake, fat and fiber intake, and behavioral correlates of BMI among overweight and obese members of a managed care organization. Int J Behav Nutr Phys Act 2006 Nov 26;3:42 [FREE Full text] [doi: 10.1186/1479-5868-3-42] [Medline: 17125525]

27. Cahill LE, Pan A, Chiuve SE, Sun Q, Willett WC, Hu FB, et al. Fried-food consumption and risk of type 2 diabetes and coronary artery disease: a prospective study in 2 cohorts of US women and men. Am J Clin Nutr 2014 Aug;100(2):667-675 [FREE Full text] [doi: 10.3945/ajcn.114.084129] [Medline: 24944061]

28. Sayon-Orea C, Martinez-Gonzalez MA, Gea A, Flores-Gomez E, Basterra-Gortari FJ, Bes-Rastrollo M. Consumption of fried foods and risk of metabolic syndrome: the SUN cohort study. Clin Nutr 2014 Jun;33(3):545-549. [doi: 10.1016/j.clnu.2013.07.014] [Medline: 23954218]

29. Özen AE, Bibiloni MDM, Bouzas C, Pons A, Tur JA. Beverage Consumption among Adults in the Balearic Islands: Association with Total Water and Energy Intake. Nutrients 2018 Aug 23;10(9):1 [FREE Full text] [doi: 10.3390/nu10091149] [Medline: 30142929]

30. Ejtahed HS, Bahadoran Z, Mirmiran P, Azizi F. Sugar-Sweetened Beverage Consumption Is Associated with Metabolic Syndrome in Iranian Adults: Tehran Lipid and Glucose Study. Endocrinol Metab (Seoul) 2015 Sep;30(3):334-342 [FREE Full text] [doi: 10.3803/EnM.2015.30.3.334] [Medline: 26435135]

31. Farrell P, Negin J, Awoke M, Thow AM, Taua M, Faumuina T, et al. Associations between sociodemographic and behaviour factors, and dietary risk factors for overweight and obesity, in Samoan women. Appetite 2019 Mar 01;134:155-161. [doi: 10.1016/j.appet.2018.12.037] [Medline: 30593836]

32. Ferretto LR, Bellei EA, Biduski D, Bin LCP, Moro MM, Cervi CR, et al. A Physical Activity Recommender System for Patients With Arterial Hypertension. IEEE Access 2020;8:61656-61664. [doi: 10.1109/access.2020.2983564]

33. Tan SL, Storm V, Reinwand DA, Wienert J, de Vries H, Lippke S. Understanding the Positive Associations of Sleep, Physical Activity, Fruit and Vegetable Intake as Predictors of Quality of Life and Subjective Health Across Age Groups: A Theory Based, Cross-Sectional Web-Based Study. Front Psychol 2018;9:977 [FREE Full text] [doi: 10.3389/fpsyg.2018.00977] [Medline: 29967588] 
34. Alakaam AAH, Lemacks JL. Fruit and Vegetable Consumption, Fat Intake, and Physical Activity Participation in Relation to Socio-demographic Factors Among Medically Underserved Adults. AIMS Public Health 2015;2(3):402-410 [FREE Full text] [doi: 10.3934/publichealth.2015.3.402] [Medline: 29546116]

35. Sebastian RS, Wilkinson Enns C, Goldman JD, Hoy MK, Moshfegh AJ. Findings from What We Eat in America, National Health and Nutrition Examination Survey 2011-2014 support salad consumption as an effective strategy for improving adherence to dietary recommendations. Public Health Nutr 2019 Apr;22(6):976-987. [doi: 10.1017/S1368980018003695] [Medline: 30767843]

36. Rimm EB, Ascherio A, Giovannucci E, Spiegelman D, Stampfer MJ, Willett WC. Vegetable, fruit, and cereal fiber intake and risk of coronary heart disease among men. JAMA 1996 Feb 14;275(6):447-451. [doi:

10.1001/jama.1996.03530300031036] [Medline: $\underline{8627965]}$

37. Miedema MD, Petrone A, Shikany JM, Greenland P, Lewis CE, Pletcher MJ, et al. Association of Fruit and Vegetable Consumption During Early Adulthood With the Prevalence of Coronary Artery Calcium After 20 Years of Follow-Up: The Coronary Artery Risk Development in Young Adults (CARDIA) Study. Circulation 2015 Nov 24;132(21):1990-1998 [FREE Full text] [doi: 10.1161/CIRCULATIONAHA.114.012562] [Medline: 26503880]

38. Ley SH, Hamdy O, Mohan V, Hu FB. Prevention and management of type 2 diabetes: dietary components and nutritional strategies. The Lancet 2014 Jun;383(9933):1999-2007. [doi: 10.1016/S0140-6736(14)60613-9]

39. Rangan AM, Tieleman L, Louie JCY, Tang LM, Hebden L, Roy R, et al. Electronic Dietary Intake Assessment (e-DIA): relative validity of a mobile phone application to measure intake of food groups. Br J Nutr 2016 Jun;115(12):2219-2226. [doi: 10.1017/S0007114516001525] [Medline: 27121045]

40. Bucher Della Torre S, Carrard I, Farina E, Danuser B, Kruseman M. Development and Evaluation of e-CA, an Electronic Mobile-Based Food Record. Nutrients 2017 Jan 18;9(1):1 [FREE Full text] [doi: 10.3390/nu9010076] [Medline: 28106767]

41. Maunder K, Walton K, Williams P, Ferguson M, Beck E. eHealth readiness of dietitians. J Hum Nutr Diet 2018 Aug;31(4):573-583. [doi: 10.1111/jhn.12542] [Medline: 29473238]

42. De Marchi ACB, Alves ALSA, Gonçalves CBC, Cervi CR, Biduski D, Bellei EA, et al. An Electronic Health Platform for Monitoring Health Conditions of Patients With Hypertension in the Brazilian Public Health System: Protocol for a Nonrandomized Controlled Trial. JMIR Res Protoc 2020 Jan 20;9(1):e15299 [FREE Full text] [doi: 10.2196/15299] [Medline: $\underline{31958068]}$

43. Roman MK, Bellei EA, Biduski D, Pasqualotti A, De Araujo CDSR, De Marchi ACB. "Hey assistant, how can I become a donor?" The case of a conversational agent designed to engage people in blood donation. J Biomed Inform 2020 Jul;107:103461 [FREE Full text] [doi: 10.1016/j.jbi.2020.103461] [Medline: $\underline{\text { 32504669] }}$

\section{Abbreviations}

CAPES: Coordination and Improvement of Higher Level or Education Personnel

CNPq: National Council for Scientific and Technological Development

FAPERGS: State Funding Agency of Rio Grande do Sul

HbA $_{1 \mathbf{c}}$ : glycated hemoglobin

SISVAN: Food and Nutrition Surveillance System of Brazil

T2DM: type 2 diabetes mellitus

TAM: Technology Acceptance Model

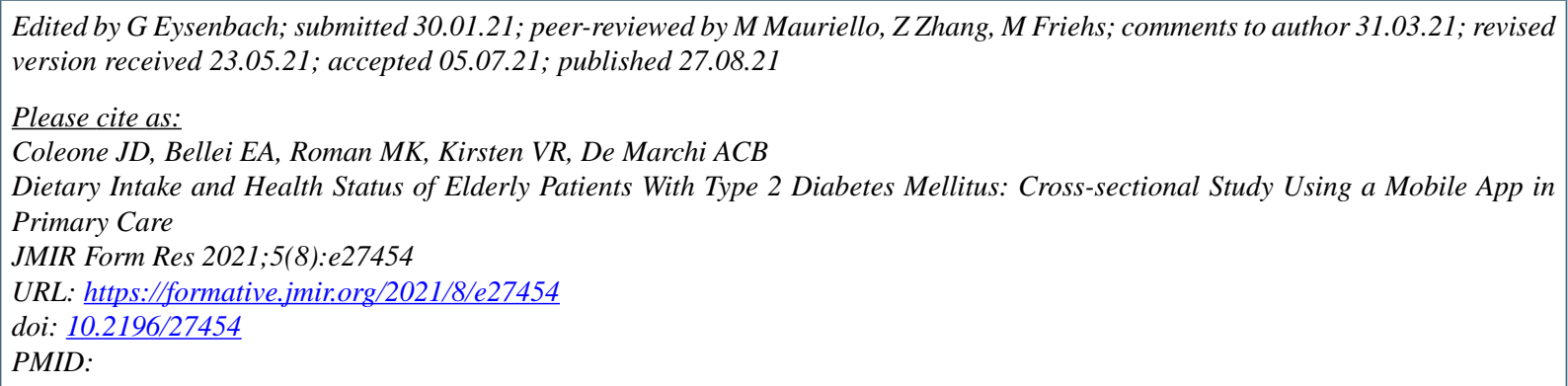

(CJoane Diomara Coleone, Ericles Andrei Bellei, Mateus Klein Roman, Vanessa Ramos Kirsten, Ana Carolina Bertoletti De Marchi. Originally published in JMIR Formative Research (https://formative.jmir.org), 27.08.2021. This is an open-access article distributed under the terms of the Creative Commons Attribution License (https://creativecommons.org/licenses/by/4.0/), which permits unrestricted use, distribution, and reproduction in any medium, provided the original work, first published in JMIR 
Formative Research, is properly cited. The complete bibliographic information, a link to the original publication on https://formative.jmir.org, as well as this copyright and license information must be included. 